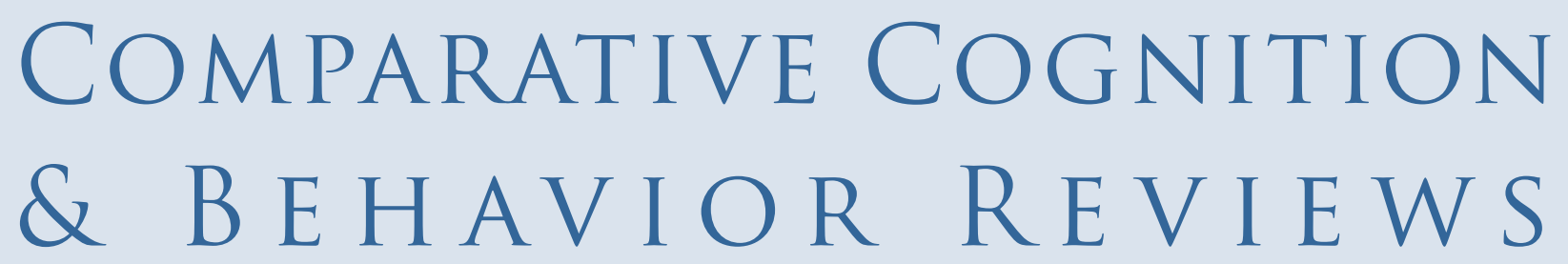

\title{
Comparative Cognition Outside the Laboratory
}

\author{
Suzanne E. MacDonald and Sarah Ritvo \\ Department of Psychology, York University, Toronto, ON, Canada
}

With its roots firmly planted in behaviorist and animal learning traditions, lab-based research is an enduring and pervasive characteristic of comparative cognition. In this review, we discuss progress in comparative cognition research in other experimental settings such as zoos, captive animal parks, and wild settings. Zoos provide access to a large array of species housed in seminatural environments that allow a reasonable degree of experimental control. Thanks to the advent of computer technology, a wide range of complex cognitive processes is increasingly being successfully studied in zoo environments. Further, cognitive research provides enrichment for captive animal participants, reducing anxiety and promoting psychological well-being. The results of cognitive research also benefit the welfare of captive animals through preference assessment, species-specific exhibit design, and behavioral management. Field settings also offer unique advantages and have allowed researchers to systematically study such diverse topics as spatial cognition, cultural transmission, problem solving, and preference. Not only does field research expand our understanding of the evolutionary and ecological drivers of animal cognition, but it also can directly inform conservation efforts. Although venturing out of the lab presents tangible challenges, including the restriction of testable hypotheses and conclusions that can be inferred from results, the benefits to be gained outweigh the costs.

Keywords: comparative, cognition, application, primate, enrichment, behavioral management; wildlife; field studies; preference

Comparative cognition is a new field, the birth of which is often traced back to the publication of two influential books just over 30 years ago (Hulse, Fowler, \& Honig, 1978; Roitblat, Bever, \& Terrace, 1984). Of course, the roots of the field are much older, dating back to Thorndike, Tolman, Skinner, and the animal learning theorists of the middle of the last century. With the onset of the cognitive revolution in the 1970s, the focus of traditional animal learning expanded to include such daring (for the time) topics as short-term memory (e.g., Roberts \& Grant, 1976), spatial memory (Olton \& Samuelson, 1976), and abstract concept formation in animals (e.g., Zentall \& Hogan, 1974). The types of questions being asked about animal brains became much more similar to those being asked about human brains.

What did not change was the way the questions were addressed. Early animal cognition research was done in the same laboratories that had previously studied animal learning, with the addition of larger and more complex environments, like the water maze (Morris, 1984) and variants on the radial arm maze (e.g., Suzuki, Augerinos, \& Black, 1980). The ecological niche of the species studied also began to be considered, with the animals given more freedom to explore and forage naturally (e.g., Spetch \& Honig, 1988). The idea that evolution might have resulted in species-specific 
cognitive abilities, with potentially diverse underlying mechanisms (Shettleworth, 1972), was a driving feature for the new field of comparative cognition. The discovery that food-storing birds demonstrated astounding spatial memory abilities (e.g., Shettleworth, 1990; Shettleworth \& Krebs, 1982) resulted in a dramatic increase in the number of taxa and individual species studied. What remained constant for most comparative cognition researchers, however, was the focus on bringing these species-specific behaviors into a laboratory setting to tease apart the variables influencing the behaviors. However, some researchers gradually began to venture out of the laboratory into other settings, such as zoos, wild animal parks, and wild settings.

\section{Studying Comparative Cognition in Zoos}

Zoos have been around for many hundreds of years, and have evolved along with our views on animals (Baratay \& Hardouin-Fugier, 2003; Kisling, 2000). Although Egyptian rulers kept animals in captivity dating back to $1500 \mathrm{BC}$, the first publicly accessible "menageries" date back to Europe in the 1700s. The first Zoological Garden, the precursor of modern zoos, opened in London in 1828, with a wide variety of exotic animals displayed in cages to the wonderment of visitors. For the past 40 years, modern zoos have strived to create environments that mimic the natural setting of the particular species, with more or less success. In most zoos, however, the legacy of the zoological garden lives on, with different species physically separated from each other. To a comparative psychologist, many zoos resemble a very large laboratory (without per diem charges!), with a range of species that Darwin would envy. Testing closely related species with different ecological niches to explore possible adaptive specializations of cognitive processes (e.g., Brodbeck \& Shettleworth, 1995; Krebs, Healy, \& Shettleworth, 1990; Pravosudov \& Clayton, 2002; Sherry, Jacobs, \& Gaulin, 1992) in a zoo setting becomes much easier. Another advantage found in most zoos is the relatively large degree of experimental control over the environment. Zoo animals are housed with similar routines to those found in laboratory settings, moving into their public exhibit areas in the morning and back into their private holding spaces in the evening. This allows researchers the ability to enter exhibit spaces without the animals present, to alter the environmental cues,

Author Note: Dr. Suzanne E. MacDonald, Department of Psychology, York University, Toronto, ON M3J 1 P3.

Correspondence concerning this article should be addressed to Dr. SuzanneE.MacDonaldatsuzmac@yorku.ca. or to position experimental stimuli. Sample size is by necessity much smaller than that possible in lab settings, and individual life histories can vary wildly, depending on whether the animals are captive or wild born. But some questions can be addressed effectively (Saudargas \& Drummer, 1996), and some species, like nonhuman primates, are particularly well suited as subjects for zoo research, as many primate species are neophilic (e.g., Day, Coe, Kendal, \& Laland, 2003; Joubert \& Vauclair, 1986) and readily explore new objects in their environment (e.g., MacDonald \& Pinel, 1991).

Nonhuman primate cognition has always been a topic of interest to comparative cognition researchers. Not only are nonhuman primates our closest living relatives, but they also offer a wide array of closely related species with different ecological and social niches. However, maintaining primates in lab settings is costly, and can be ethically questionable for many species, especially the great apes. Primates that live in zoos offer an opportunity to collect much-needed basic cognitive data on species that would otherwise not be available for study. Because of the inherent difficulty in obtaining control over experimental variables like life history or individual experience, much of the early research in zoo settings focused on whether a species could do a particular task. For example, MacDonald and Wilkie (1990) used a free-foraging variant of the radial arm maze with an Old World monkey species, and found that both monkeys tested were highly accurate at remembering the location of hidden food, even after a delay of up to 24 hours. Further, both animals used a "least distance" or "traveling salesman" strategy to minimize the distance they traveled to retrieve food. This paradigm has been successfully used with other zoo-housed primate species, like New World monkeys (e.g., MacDonald, Pang, \& Gibeault, 1994) and great apes (gorillas: Gibeault \& MacDonald, 2000; MacDonald, 1994; orangutans: MacDonald \& Agnes, 1999) to compare and contrast the cognitive abilities of different species. The same basic task has also been used in field settings (BiccaMarques \& Garber, 2004; Garber \& Pacuilli, 1997; Janson, 1998 ) and has provided a more complete picture of spatial cognition in the Primate order.

In addition to asking whether an animal has a particular ability, one can also ask how a species solves a cognitive problem. The search for the mechanisms underlying primate cognitive processes has moved out of the lab and into zoo settings, thanks to the advent of computer technology. Using computer touch screens in a zoo is challenging, primarily because the enclosures are not usually designed to accommodate the equipment. Data are often collected under lessthan-ideal circumstances, in small holding areas, and with limited access to the animals. Training protocols that might take a few weeks in a lab setting can often take a year or 


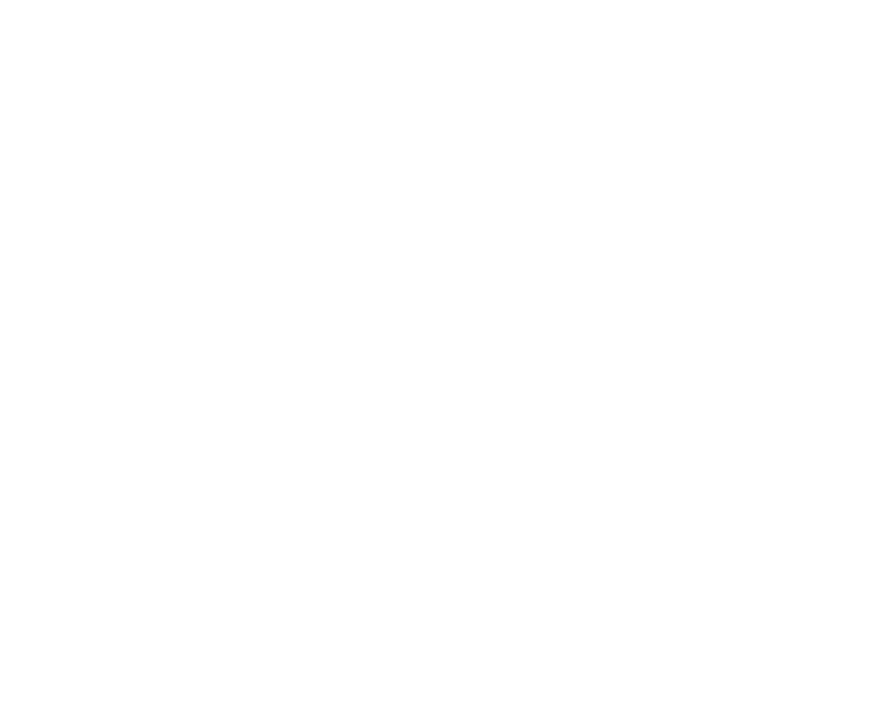

Video 1. Adult male gorilla participating in a spatial memory task at the Toronto Zoo, 1991.

http://comparative-cognition-and-behavior-reviews.org/wp/wp-content /uploads/2016/04/CCBR_03-MacDonald-Ritvo_v11-2016-video01.m4v

more in zoos, simply because the daily zoo routine does not allow for regular data collection. Isolating individual animals and eliminating the distractions present in a zoo setting are often difficult, and depend on the close cooperation of zoo staff. However, some zoos are now building exhibits centered around cognition research, which give researchers easier access and which allow members of the public to see firsthand how comparative cognition research is done. The "Think Tank" at the National Zoo in Washington, DC, is an excellent example of this type of exhibit, although many others now exist, notably at Zoo Atlanta; Wolf Park, Indiana; the Wolf Science Centre near Vienna; The Seas at Epcot in Florida; and at the Leipzig Zoo in Germany. All of these facilities serve not only to advance comparative cognition as a science, but also to educate and inform the public about the importance of our field.

In a typical experiment, a computer touch screen or test apparatus is made available to free-ranging animals, either individually or in a group setting, and the animal(s) can interact with the screen and researcher if they so choose. Reinforcement is typically given manually, although some purpose-built exhibits have automated the process so the animals can participate throughout the day. For example, Marsh, Spetch, and MacDonald (2011) investigated how orangutans (Pongo abelli) used landmarks in a spatial task presented on a computer touch screen. The animals participated individually, and they interacted with the touch screen by touching it with a wooden dowel. On each trial, a square

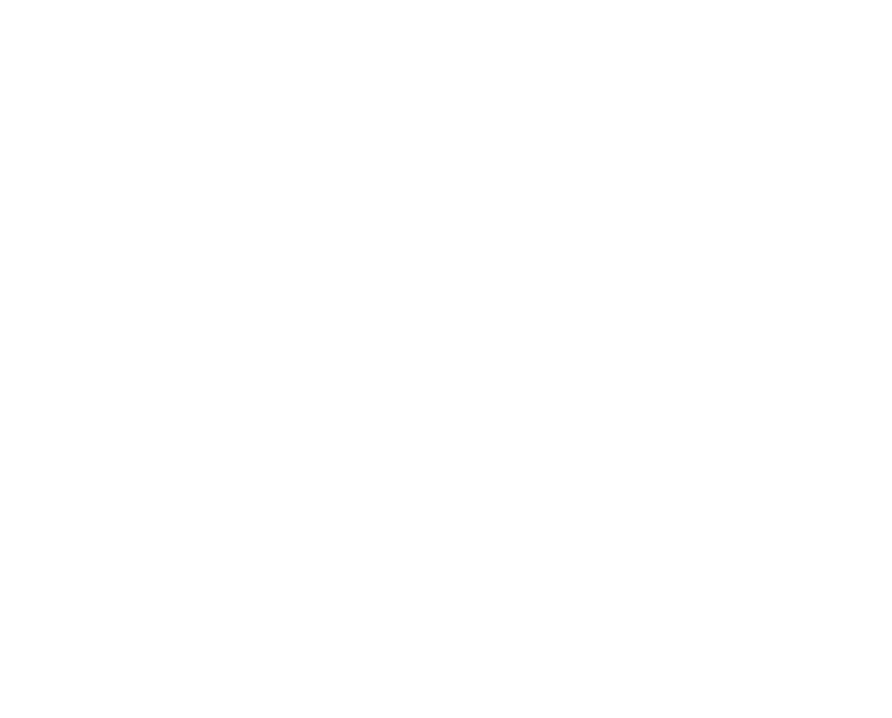

Video 2. Adult female Old World monkey (Cercopithecus ascanius whitesidei) participating in a spatial memory task at the Stanley Park Zoo, 1989

http://comparative-cognition-and-behavior-reviews.org/wp/wp-content /uploads/2016/04/CCBR_03-MacDonald-Ritvo_v11-2016-video02.m4v

array of two-dimensional "landmarks" were presented at a random location on the touch screen. Orangutans were trained to locate the goal hidden in the center of the array, and then were given an expansion task, in which the distance between the landmarks was increased, while maintaining the same geometric relationship between them. Unlike human adults, who continue to search in the "middle" of the array on expansion tasks (MacDonald, Spetch, Kelly, \& Cheng, 2004), the orangutans focused their searching along absolute directional vectors from the individual landmarks. An unexpected advantage to doing this type of research in a zoo setting is that the opportunity to collect comparable data from human children - zoo visitors - often exists when the task is one that can be completed in a few minutes, while children are visiting the animals' exhibit with their parents. In this way, Marsh et al. (2011) and Marsh, Adams, Floyd, and MacDonald (2013) were able to collect directly comparable data from children across a wide age range, without the usual delay and time commitments necessary to obtain data from children in school settings.

Complex cognitive processes, including imitation (e.g., Stoinski, Wrate, Ure \& Whiten, 2001), numerosity judgments (e.g., Anderson et al., 2005), categorization and concept formation (e.g., Marsh \& MacDonald, 2008; Vonk $\&$ MacDonald, 2002, 2004), and metacognition (e.g., Marsh \& MacDonald, 2011, 2012) have all been studied in zoohoused primates, and the list of institutions establishing cognitive research programs for their animals is growing 


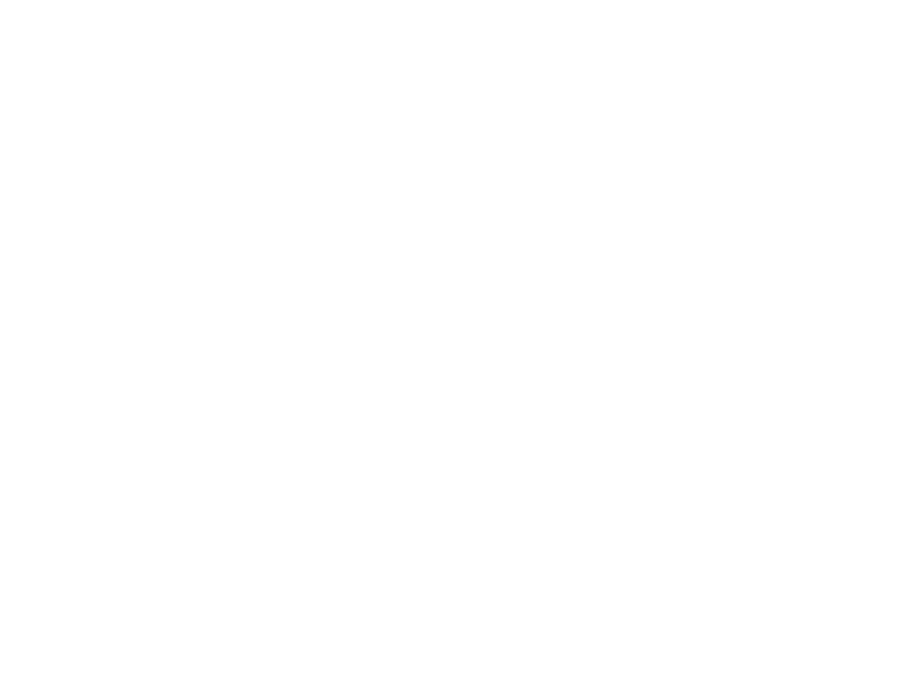

Video 3. Computer touch screen used by the orangutans at the Toronto Zoo.

http://comparative-cognition-and-behavior-reviews.org/wp/wp-content /uploads/2016/04/CCBR_03-MacDonald-Ritvo_v11-2016-video03.m4v

every day. Complex cognition is now being investigated in other taxa as well, often in species that cannot be easily studied in either lab or field settings. For example, Asian elephants have demonstrated sophisticated cooperative behavior (Foerder, Galloway, Barthel, Moore, \& Reiss, 2011; Plotnik, Lair, Suphachoksahakun, \& de Waal, 2011) as well as tool use (Hart, Hart, McCoy, \& Sarath, 2001; Whiten, Horner \& de Waal, 2005) and self-recognition (Plotnik, de Waal, \& Reiss, 2006). Similarly, dolphins at Disney's Epcot Center have been participating in cognitive research for over 25 years (e.g., Harley, Fellner, \& Stamper, 2010). Dolphins use their astonishing echolocation and communicative abilities to allow researchers to study echoic object and shape recognition (e.g., Harley \& DeLong, 2008), as well as more cognitively complex behaviors such as pointing (Xitco, Gory, \& Kuczaj, 2001, 2004). The ability to carefully control environmental cues and experimental stimuli in an aquarium setting allows for insights into dolphin cognition that would be next to impossible to gain in the wild.

An overarching benefit of all cognition research in zoos is the cognitive stimulation that the participants receive while doing various experimental tasks. Participating in cognitive research is increasingly seen as an important form of enrichment for captive animals, as a means of keeping individuals mentally stimulated (e.g., Mason, Clubb, Latham, \& Vickery, 2007). Modern zoos are moving away from the traditional "environmental" enrichment paradigm to one of behavioral management (Tresz, 2006; Weed \& O’Neill-Wagner, 2015), although this has been a slow process. Forthman \& Ogden (1992) were among the first to call for a new focus on the cognitive and social requirements of animals when designing zoo exhibits and daily routines. Since then, the tools of comparative cognition and applied behavior analysis have been adopted by many zoos, and have been used effectively in a wide range of contexts, from determining appropriate breeding partners (Watters \& Powell, 2012) to reducing aggression in chimpanzees (Bloomsmith, Laule, Alford, \& Thurston, 1994), to improving exhibit design for primates (Hosey, 2005; Hosey \& Druck, 1987), to reducing anxietyrelated behavior in polar bears (Kelly, Harrison, Size, \& MacDonald, 2015; Renner \& Kelly, 2006).

Reducing anxiety and promoting psychological wellbeing in captive animals is an important goal for zoos, both from an animal welfare standpoint and to ensure that highly endangered species breed successfully in captivity. Providing stimulation to relieve boredom is common; however, until recently, assessing how stimuli are perceived by the animals has not been a priority in many zoos. Comparative cognition methods can be used effectively to evaluate these interventions, and to suggest new stimuli that may be effective, based on the cognitive abilities of target species. For example, music is consistently used as environmental enrichment in primate facilities around the world, under the assumption that music is as engaging for animals as it is for humans (Hinds, Raimond, \& Purcell, 2007; Lutz \& Novak, 2005). For the most part, music selection is based on the preferences of human facilitators despite the fact that there is little to no indication that human and nonhuman music preferences correspond (Lutz \& Novak, 2005).

A complication of this area of study from both a theoretical and a methodological standpoint relates to preference assessment in subjects generally incapable of directly communicating internal sentiments. Solutions to this challenge have been sourced from human infant preference assessment literature. Review of established methodologies indicate three main approaches: (a) behavioral observation during stimulus exposure, (b) the least-aversive or most-desired choice paradigm, and (c) participant-controlled procedures (Ritvo \& Allison, 2014). Participant-controlled procedures uniquely allow subjects to spontaneously and autonomously choose the type and duration of stimulus exposure. This makes participant-controlled procedures the most precise and appropriate approach for inferring that subjects "like" one stimulus more than another, as opposed to "dislike" one stimulus less than another and is, consequently, a recommended methodology for assessing nonhuman primate preferences (Lamont, 2005; Ritvo \& Allison, 2014; Ritvo \& MacDonald, unpublished manuscript).

Accordingly, Ritvo and MacDonald (unpublished manuscript) employed a participant-controlled 
dichotomous-choice design in their investigation of music preference and discrimination in Sumatran orangutans (Pongo abelli). Three orangutans at the Toronto Zoo, two females (ages 21 and 28) and one male (age: 6), were trained to indicate preference via touch screen choices. Six music genres were tested based on conventional and popular North American genres that subjects would be familiar with (i.e., via radio music employed as auditory enrichment at the Toronto Zoo). A seventh genre, Tuva throat singing, was also selected because both the music and the way it is physically produced resemble orangutan long calls. Specific genre exemplars were selected based on human preference indicated by the greatest number of purchases on iTunes (Apple Inc., 2013).

In Study 1, preference for music vs. silence was explored. Following exposure to a sample of one of the seven music genres, subjects chose to continue to listen to the music sample previously played by touching one side of the screen, or to listen to the equivalent duration of silence instead by touching the other side of the screen. In Study 2, orangutans' ability to discriminate music from scrambled music was assessed using a standard delayed matching-to-sample (DMTS) task. In one condition, orangutans were rewarded for correct classification via touch screen of auditory stimuli as "music" or "scrambled music." In the second, control condition, subjects were rewarded for correct classification via touch screen of auditory stimuli as a female zookeeper's voice or a male zookeeper's voice. Contrary to expectation, results indicated that (a) subjects preferred silence to music (or were indifferent), (b) they did not display a preference for any specific musical genre employed, (c) they did not discriminate "music" from "scrambled music," and (d) only a single female discriminated between a male zookeeper's and a female zookeeper's voices.

Given that the orangutans tended to choose silence or to stop participating entirely during times of alarm or commotion, their preference for silence over music may relate to the potential for music to mask valuable information that other auditory stimuli provide, (e.g., food is being prepared or conspecifics are distressed). However, the results of Study 2 imply a more profound explanation; orangutans do not perceive music analogously to humans. In particular, results suggest that human-defined music exemplars and scrambled versions of the same music were not qualitatively discerned by orangutans. This finding could explain why the orangutans did not appear to find the music employed in Study 1 appealing. Whereas humans perceive music as a united, stable, rhythmic and harmonious stimulus, orangutans may not perceive music as qualitatively different from other fluctuating auditory stimuli, or they may perceive music as more akin to indiscriminate noise. Antagonistic behavior observed in Study 1 supports this explanation, suggesting that our participants found humandefined music to be mild-to-moderately aversive.

In either case, our results suggest that the music employed in these investigations was not rewarding for the orangutans. Consequently, the common practice of using Western music as an enrichment tool in primate care facilities appears unfounded and could in fact result in negative behavioral or psychological effects. Whether other species have similar reactions to music enrichment remains to be empirically tested. What is key to this type of research, though, is the idea of preference or choice on the part of the animal.

This issue has recently received a lot of public attention with the ongoing court battle in Argentina to grant Sandra, a 29-year-old female Sumatran orangutan housed in the Buenos Aires Zoo, human rights on the basis of her cognitive capacities (Jacobs, 2015). Zoos around the world are following this court case with interest, and regardless of the final ruling, it has brought to the forefront the issue of an animal's right to control aspects of its captive home, such as when and what to eat, where to sleep, and with whom to socialize. Comparative cognition researchers can assist zoos in designing exhibits that make the most of animals' species-specific cognitive abilities, thus improving animal welfare and building the new scientific field of behavioral management.

\section{Studying Comparative Cognition in the Wild}

Behavioral ecologists have been studying cognitive processes in the field for decades. Comparative cognition researchers coming out of the animal learning tradition are now realizing the exciting potential of expanding their research to include data from animals living in the wild. Of course, field settings are much more challenging places in which to work from a practical standpoint. Dealing with the costs and hassle of long-distance travel, lodging, wildlife permits, ethics approval, not to mention the ever-present contingent of biting bugs, can be a daunting prospect. More important, obtaining sufficient control over extraneous variables is often impossible. Life history information for individuals is usually absent, and so studying large, long-lived species is difficult. Just as in zoo settings, the lack of control over many environmental variables constrains the types of questions that can be asked. And, just as in the zoo setting, spatial cognition is a fertile area for study in the field. Space limitations are eliminated, and there are a large number of environmental cues that can be experimentally manipulated. Systematic, long-term, and creative field research on wild birds (e.g., Healy \& Hurly, 2004) and invertebrates like 
ants (e.g., Graham \& Cheng, 2009; Narendra, Sulikowski, \& Cheng, 2007; Wystrach, Beugnon, \& Cheng, 2012) and bees (e.g., Menzel et al., 2005) has broadened our understanding of the range of species exhibiting complex spatial abilities and, even more important, elucidated the underlying cognitive mechanisms involved.

Although working with wild animals does have some challenges, there are also some exciting opportunities to branch out and investigate behaviors that are best expressed in a complex environmental context. Cognition and culture comprise an area that is difficult to explore in lab settings, but one in which researchers who study freely behaving wild animals have been able to glean new insights. The social transmission of information has been studied extensively in chimpanzees and other primates, (e.g., Boesch \& Boesch, 1990; Huffman \& Quiatt, 1986; Inoue-Nakamura \& Matsuzawa, 1997; Kendal et al., 2010; Perry \& Manson, 2003). More recent research has shown cultural transmission and even "teaching" behavior in a range of species, including cetaceans (e.g., Greggor, 2012), meerkats (e.g., Thornton \& Raihani, 2010), and great tits (Aplin et al., 2015). Aplin et al. (2105) experimentally introduced a novel foraging behavior into a population of great tits (Parus major) and studied the dissemination and persistence of the behavior over two generations. They found that individual birds adopted social information preferentially over personal information; essentially, they preferred to learn from other birds, rather than learn by experience. This demonstration of complex cultural transmission in a non-primate species suggests that there remains much more to be learned from studying comparative cognition in wild populations.

Problem solving is another area that is a fruitful avenue for field research. Presenting individuals with a novel stimulus and observing their behavior reduces the possibility of prior learning effects. This can be done with either captive or wild animals. Extensive research on problem solving has been done with birds, including New Caledonian crows (e.g., von Bayern, Heathcote, Rutz, \& Kacelnik, 2009), keas (e.g., Auersperg, von Bayern, Gajdon, Huber, \& Kacelnik, 2011), passerines (Webster \& Lefebvre, 2001), and ravens (Heinrich \& Bugnyar, 2005). Problem solving in wild mammals is also being explored. For example, Benson-Amram \& Holekamp (2012) studied problem solving in wild spotted hyenas (Crocuta crocuta) by presenting individuals with a large puzzle box containing meat. To obtain the food, a hyena had to perform two distinct behaviors in sequence, first sliding a latch and then swinging a door. There were considerable individual differences between hyenas, and only $15 \%$ of the participants were able to solve the task, although those that tried more solutions were more successful. Similar to results from human subjects, reduced neophobia and increased exploratory behaviors were both important predictors of problem-solving success.

Undertaking field work with free-ranging species does present additional challenges. For example, MacDonald (2015) investigated problem solving and exploratory behavior in wild raccoons, comparing raccoons from an urban population with those from a rural environment. The first step in this multiyear project was to trap wild urban raccoons and fit them with GPS-collars to determine home range size and individual movement (Dupuis-Desormeaux $\&$ MacDonald, 2011). Because individual identification in wild animals is often difficult, determining the size and location of home ranges is critically important so individual animals are not sampled more than once. We found that urban home range sizes were much smaller than expected-about three square blocks--and that animal movement was constrained by busy city streets. In comparison, estimated rural home ranges for raccoons vary between 60 and 90 ha (Beasley, Devault, \& Rhodes, 2007). MacDonald (2015) then sampled raccoons from nonoverlapping home ranges throughout the greater Toronto area, and from across rural southern Ontario. Two different container types, each baited with highly preferred food, were placed in the raccoons' home ranges. One container was familiar to both urban and rural animals: a standard 40-liter garbage can, fitted with a "bungee" cord across the lid to hold it in place. One container was novel: a hanging bucket suspended $30 \mathrm{~cm}$ above the ground from a rope anchored to nearby trees. The baited locations were equipped with motion-capture infrared tracking cameras, which recorded video in complete darkness. More than 120 tracking nights over a two-year period resulted in 800 hours of video. After eliminating data from a wide range of other species (domestic cats, coyotes, and black bears were the most common), and only using data from an individual raccoon's first encounter with the objects, a total of 22 rural and 22 urban samples remained. Contrary to predictions, the novel object was explored and depleted quickly by all the urban raccoons and by their rural counterparts. Although the hanging object did move and spin in an unpredictable manner, locating the hidden food contained inside was a simple one-stage process. However, the familiar object - the garbage can - proved to be more of a challenge than expected for the rural animals. While 17 of the 22 urban animals successfully depleted the food from the can, none of the 22 rural raccoons were successful, despite many attempts. The urban animals were much more persistent in manipulating the object, and they also employed additional strategies not observed in the rural animals. This was true for both male and female animals, 
as well as young raccoons, who were at the time of testing only five or six months old and navigating the environment for the first time. These data support the tantalizing possibility that the anthropogenic selection is at work, with our cities - and human behavior-selecting for particular cognitive abilities in raccoons. Persistence, neophilia, and high levels of exploratory behavior may result in increased survival and reproduction in the urban setting, and thus we may be observing cognitive evolution in action in this species. Comparing the exploratory abilities and behavioral flexibility of infant raccoons from rural and urban populations is the next step to determine whether differential experience explains the gap between urban and rural raccoons, or whether these traits are heritable and stable across generations, as has been found in other wild species (e.g., great tits: Dingemanse, Both, Drent, van Oers, \& van Noordwijk, 2002; Cole, Morand-Ferron, Hinks, \& Quinn, 2012; cane toads: Candler \& Bernal, 2014; Herborn et al., 2010; freshwater fish: Smith, Philips, \& Reichard, 2015).

Just as preference and choice are becoming a topic of interest in zoo research, studying preference in wild populations can be a valuable contribution of comparative cognition to conservation efforts for endangered species. One of the most pressing current issues in the field is the effect of human-animal conflicts, which often result in the culling of "problem animals." Reducing these conflicts is vital to ensure the livelihood of human farmers and fishers, and also to ensure the continued survival of highly endangered species. The African elephant is an excellent example of this complex problem. Given the endangered status of this species, and the increasingly limited habitat available for them, reducing human conflict is essential. In many African countries, including Kenya, Zimbabwe, and South Africa, elephant migratory and ranging patterns traverse lands owned by subsistence farmers (e.g., Hoare, 1999; Loarie, van Aarde, \& Pimm, 2009). Crop raiding by elephants can destroy an entire year's harvest in a single night (Sitati \& Walpole, 2006), so tensions are understandably high between farmers and elephant herds. To date, the focus has been on training elephants to avoid human habitation and fences, using a variety of stimuli as punishers, including the sound of angry bees (King, Douglas-Hamilton, \& Vollrath, 2007), electrified fences, beating drums, throwing rocks, firecrackers, chili peppers, and cowbells (e.g., Osborn \& Parker, 2002, 2003; Sitati, Walpole, \& Leader-Williams, 2005). Currently, Zitzer \& MacDonald (2015) are exploring the "flip side" of avoidance, looking at elephant food and olfactory preferences, with the goal of using positive reinforcement to encourage elephants to choose alternative routes, away from human settlements. We are using motion-capture tracking

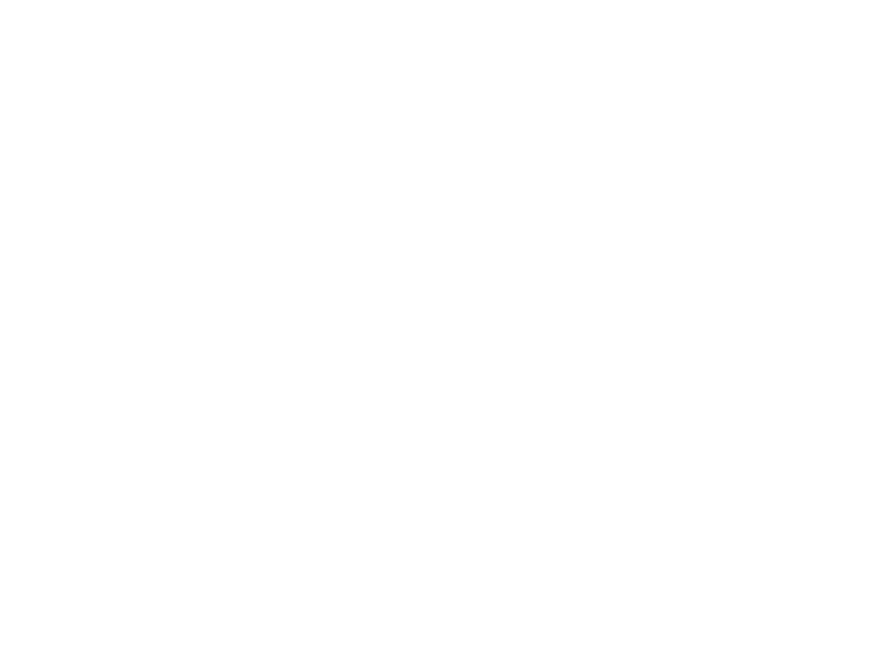

Video 4. Urban raccoon attempting the food bucket task. http://comparative-cognition-and-behavior-reviews.org/wp/wp-content /uploads/2016/04/CCBR_03-MacDonald-Ritvo_v11-2016-video04.m4v

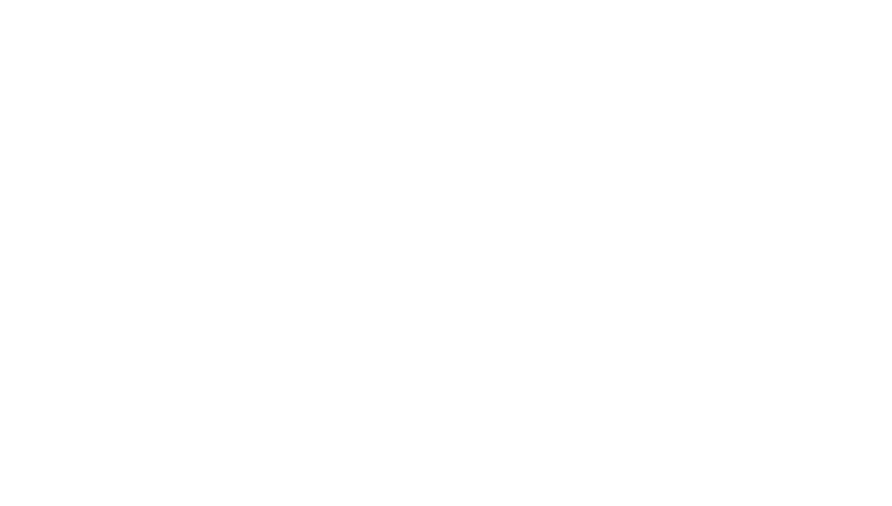

Video 5. Wild raccoon attempting the food bucket task. http://comparative-cognition-and-behavior-reviews.org/wp/wp-content /uploads/2016/04/CCBR_03-MacDonald-Ritvo_v11-2016-video05.m4v

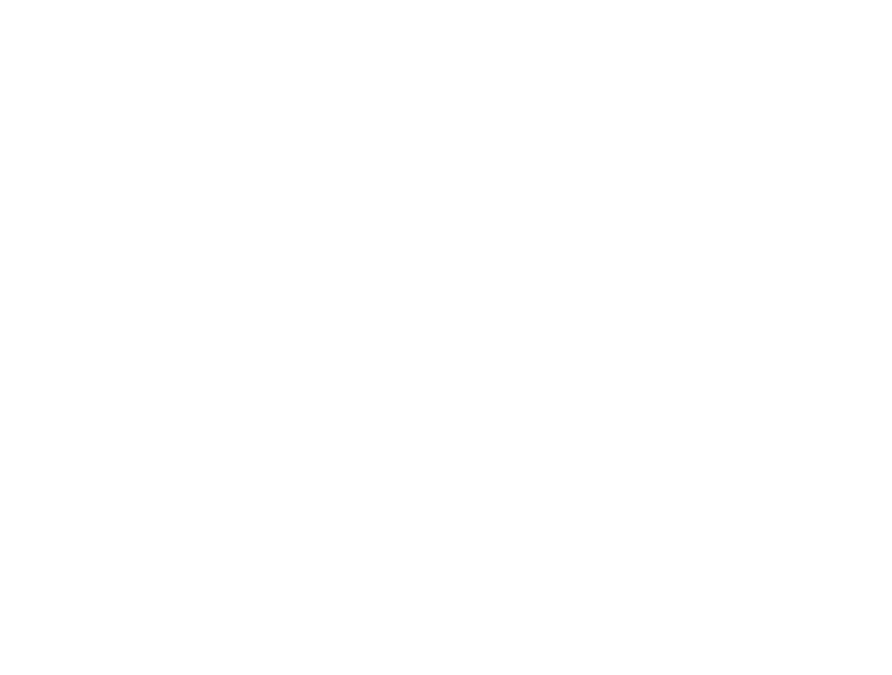

Video 6. Urban raccoon family attempting the garbage can task. (This illustrates the difficulty in obtaining data from individual animals in a wild setting!)

http://comparative-cognition-and-behavior-reviews.org/wp/wp-content /uploads/2016/04/CCBR 03-MacDonald-Ritvo v11-2016-video06.m4v 
cameras in the field in South Africa to measure which natural vegetation items elephants choose in an experimental preference test (akin to a large buffet for elephants). We are combining these preference data with vegetation surveys to look at the damage done by elephants in a range of habitats. The preference and habitat data will provide concrete information to local landowners about the real effect that elephants are having on the landscape, and will also provide positive solutions to mitigate conflicts in the future. Of course, this is just one example. Many more opportunities exist for fruitful collaborations between comparative cognition researchers and conservationists, as nicely outlined by Greggor, Clayton, Phalan, \& Thornton (2014).

\section{Conclusions}

Venturing out of the lab is not easy. Reduced experimental control can restrict the types of hypotheses that can be tested and may limit the conclusions that can be drawn from results. Establishing cognitive mechanisms can be difficult with so many potential confounding variables. There may be significant financial costs, as well as time and effort involved in conducting long-term studies that may be dependent on weather and limited by unreliable access. However, the benefits to be gained far outweigh the costs. Extending the range of species with whom we work will result in truly comparative research, and lead to a better understanding of the diverse ways that evolution has shaped the brains of animals, both human and nonhuman. Results from zoo and field settings can inform and inspire lab-based research, and vice versa. Placing a species in its ecological context can lead to new empirical questions and exciting new directions for research. In these days of uncertain, limited funding and public distrust of lab-based animal research, it is more important than ever to share our comparative approach and methods and collaborate with local institutions and communities.

\section{References}

Anderson, U. S., Stoinski, T. S., Bloomsmith, M. A., Marr, M. J., Smith, A. D., \& Maple, T. L. (2005). Relative numerousness judgment and summation in young and old Western lowland gorillas. Journal of Comparative Psychology, 119(3), 285-295. doi:10.1037/0735-7036.119.3.285
Aplin, L. M., Farine, D. R., Morand-Ferron, J., Cockburn, A., Thornton, A., \& Sheldon, B. C. (2015). Experimentally induced innovations lead to persistent culture via conformity in wild birds. Nature, 518(7540), 538-541. doi:10.1038/nature13998

Apple, Inc. (2013). iTunes application software. Retrieved from http://itunes.apple.com.

Auersperg, A. M. I., von Bayern, A. M. P., Gajdon, G. K., Huber, L., \& Kacelnik, A. (2011).

Flexibility in problem solving and tool use of kea and New Caledonian crows in a multi access box paradigm. PLOS ONE, 6(6), e20231. doi:10.1371/journal.pone.0020231

Baratay, E., \& Hardouin-Fugier, E. (2003). Zoo: A history of zoological gardens in the West. London, England: Reaktion Books.

Beasley, J. C., Devault, T. L., \& Rhodes, O. E. (2007). Home-range attributes of raccoons in a fragmented agricultural region of northern Indiana. The Journal of Wildlife Management, 71(3), 844-850. doi:10.2193/2006-022

Benson-Amram, S., \& Holekamp, K. E. (2012). Innovative problem solving by wild spotted hyenas. Proceedings of the Royal Society of London B: Biological Sciences, rspb20121450. doi:10.1098/rspb.2012.1450

Bergman, T. J., \& Kitchen, D. M. (2008). Comparing responses to novel objects in wild baboons (Papio ursinus) and geladas (Theropithecus gelada). Animal Cognition, 12(1), 63-73. doi:10.1007/s10071-008-0171-2

Bicca-Marques, J. C., \& Garber, P. A. (2004). Use of spatial, visual, and olfactory information during foraging in wild nocturnal and diurnal anthropoids: A field experiment comparing Aotus, Callicebus, and Saguinus. American Journal of Primatology, 62(3), 171-187. doi:10.1002/ajp.20014

Bloomsmith, M. A., Laule, G. E., Alford, P. L., \& Thurston, R. H. (1994). Using training to moderate chimpanzee aggression during feeding. Zoo Biology, 13(6), 557-566. doi:10.1002/zoo.1430130605 
Boesch, C., \& Boesch, H. (1990). Tool use and tool making in wild chimpanzees. Folia Primatologica, 54(1-2), 86-99. doi:10.1159/000156428

Brodbeck, D. R., \& Shettleworth, S. J. (1995). Matching location and color of a compound stimulus: Comparison of a food-storing and a nonstoring bird species. Journal of Experimental Psychology: Animal Behavior Processes, 21(1), 64. doi:10.1037/0097-7403.21.1.64

Candler, S., \& Bernal, X. E. (2014). Differences in neophobia between cane toads from introduced and native populations. Behavioral Ecology, aru162. doi:10.1093/beheco/aru162

Cole, E. F., Morand-Ferron, J., Hinks, A. E., \& Quinn, J. L. (2012). Cognitive ability influences reproductive life history variation in the wild. Current Biology, 22(19), 1808-1812. doi:10.1016/j.cub.2012.07.051

Day, R. L., Coe, R. L., Kendal, J. R., \& Laland, K. N. (2003). Neophilia, innovation and social learning: A study of intergeneric differences in callitrichid monkeys. Animal Behaviour, 65(3), 559-571. doi:10.1006/anbe.2003.2074

Dingemanse, N. J., Both, C., Drent, P. J., van Oers, K., \& van Noordwijk, A. J. (2002). Repeatability and heritability of exploratory behaviour in great tits from the wild. Animal Behaviour, 64(6), 929-938. doi:10.1006/anbe.2002.2006

Dupuis-Desormeaux, M., \& MacDonald, S. E. (2011, August). Behavior and movement patterns of urban raccoons (Procyon lotor). Paper presented at symposium Exploring the self-worlds of nonhuman animals via advances in biotelemetry technology at the annual meeting of the American Psychological Association, Washington, DC.

Foerder, P., Galloway, M., Barthel, T., Moore, D. E., \& Reiss, D. (2011). Insightful problem solving in an Asian elephant. PLOS ONE, 6(8), e23251. doi:10.1371/journal.pone.0023251.

Forthman, D. L., \& Ogden, J. J. (1992). The role of applied behavior analysis in zoo management: Today and tomorrow. Journal of Applied Behavior Analysis, 25(3), 647-652. doi:10.1901/jaba.1992.25-647
Garber, P. A., \& Paciulli, L. M. (1997). Experimental field study of spatial memory and learning in wild capuchin monkeys (Cebus capucinus). Folia Primatologica, 68(3-5), 236-253. doi:10.1159/000157250

Gibeault, S., \& MacDonald, S. E. (2000). Spatial memory and foraging competition in captive western lowland gorillas (Gorilla gorilla gorilla). Primates, 41(2), 147-160. doi:10.1007/BF02557796

Graham, P., \& Cheng, K. (2009). Ants use the panoramic skyline as a visual cue during navigation. Current Biology, 19(20), R935-R937. doi:10.1016/j.cub.2009.08.015

Greggor, A. L. (2012). A functional paradigm for evaluating culture: An example with cetaceans. Current Zoology, 58(2), 271-286.

Greggor, A. L., Clayton, N. S., Phalan, B., \& Thornton, A. (2014). Comparative cognition for conservationists. Trends in Ecology \& Evolution, 29(9), 489-495. doi:10.1016/j.tree.2014.06.004

Harley, H. E., \& DeLong, C. M. (2008). Echoic object recognition by the bottlenose dolphin. Comparative Cognition and Behavior Reviews, 3, 46-65. doi:10.3819/ccbr.2008.30003

Harley, H. E., Fellner, W., \& Stamper, M. A. (2010). Cognitive research with dolphins (Tursiops truncates) at Disney's The Seas: A program for enrichment, science, education and conservation. International Journal of Comparative Psychology, 23, 331-343.

Hart, B. L., Hart, L. A., McCoy, M. and Sarath, C. R. (2001). Cognitive behaviour in Asian elephants: Use and modification of branches for fly switching. Animal Behaviour, 62(5), 839-47. doi:10.1006/anbe.2001.1815.

Healy, S. D., \& Hurly, T. A. (2004). Spatial learning and memory in birds. Brain, Behavior and Evolution, 63(4), 211-220. doi:10.1159/000076782

Heinrich, B., \& Bugnyar, T. (2005). Testing problem solving in ravens: String-pulling to reach food. Ethology, 111(10), 962-976. doi:10.1111/j.1439-0310.2005.01133.x 
Herborn, K. A., Macleod, R., Miles, W. T. S., Schofield, A. N. B., Alexander, L., \& Arnold, K. E. (2010). Personality in captivity reflects personality in the wild. Animal Behaviour, 79(4), 835-843. doi:10.1016/j.anbehav.2009.12.026

Hinds, S. B., Raimond, S., \& Purcell, B. K. (2007). The effect of harp music on heart rate, mean blood pressure, respiratory rate, and body temperature in the African green monkey. Journal of Medical Primatology, 36(2), 95-100. doi:10.1111/j.1600-0684.2006.00157.x

Hoare, R. E. (1999). Determinants of humanelephant conflict in a land-use mosaic. Journal of Applied Ecology, 36(5), 689-700. doi:10.1046/j.1365-2664.1999.00437.x

Hosey, G. R. (2005). How does the zoo environment affect the behaviour of captive primates? Applied Animal Behaviour Science, 90(2), 107-129. doi:10.1016/j.applanim.2004.08.015

Hosey, G. R., \& Druck, P. L. (1987). The influence of zoo visitors on the behaviour of captive primates. Applied Animal Behaviour Science, 18(1), 19-29. doi:10.1016/0168-1591(87)90251-6

Huffman, M. A., \& Quiatt, D. (1986). Stone handling by Japanese macaques (Macaca fuscata): Implications for tool use of stone. Primates, 27(4), 413-423. doi:10.1007/BF02381887

Hulse, S. H., Fowler, H., \& Honig, W. K. (Eds.). (1978). Cognitive processes in animal behavior. Hillsdale, NJ: Lawrence Erlbaum. Retrieved from http://psycnet.apa.org/psycinfo/1980-51406-000

Inoue-Nakamura, N., \& Matsuzawa, T. (1997). Development of stone tool use by wild chimpanzees (Pan troglodytes). Journal of Comparative Psychology, 111(2), 159. doi:10.1037/0735-7036.111.2.159

Jacobs, S. (2015). Orangutan named Sandra fights for freedom in Argentina court. Retrieved May 21, 2015, from http://www.smh.com.au/environment/animals /orangutan-named-sandra-fights-for-freedom-in -argentina-court-20150521-gh6f3e.html
Janson, C. H. (1998). Experimental evidence for spatial memory in foraging wild capuchin monkeys, Cebus apella. Animal Behaviour, 55(5), 1229-1243. doi:10.1006/anbe.1997.0688

Joubert, A., \& Vauclair, J. (1986). Reaction to novel objects in a troop of Guinea baboons: Approach and manipulation. Behaviour, 96(1), 92-104. doi:10.1163/156853986X00234

Kelly, K. R., Harrison, M. L., Size, D. D., \& MacDonald, S. E. (2015). Individual effects of seasonal changes, visitor density, and concurrent bear behavior on stereotypical behaviors in captive polar bears (Ursus maritimus). Journal of Applied Animal Welfare Science, 18(1), 17-31. doi:10.1080/10888705.2014.924832

Kendal, R. L., Custance, D. M., Kendal, J. R., Vale, G., Stoinski, T. S., Rakotomalala, N. L., \& Rasamimanana, H. (2010). Evidence for social learning in wild lemurs (Lemur catta). Learning \& Behavior, 38(3), 220-234. doi:10.3758/LB.38.3.220

King, L. E., Douglas-Hamilton, I., \& Vollrath, F. (2007). African elephants run from the sound of disturbed bees. Current Biology, 17(19), R832-R833. doi:10.1016/j.cub.2007.07.038

Kisling, V. N. (Ed.). (2000). Zoo and aquarium history: Ancient animal collections to zoological gardens. Boca Raton, Florida: CRC Press. doi:10.1201/9781420039245

Krebs, J. R., Healy, S. D., \& Shettleworth, S. J. (1990). Spatial memory of Paridae: Comparison of a storing and a non-storing species, the coal tit, Parus ater, and the great tit, P. major. Animal Behaviour, 39(6), 11271137. doi:10.1016/S0003-3472(05)80785-7

Lamont, A. M. (2005). What do monkeys' music choices mean? Trends in Cognitive Sciences, 9(8), 359-361. doi:10.1016/j.tics.2005.06.014

Loarie, S. R., van Aarde, R. J., \& Pimm, S. L. (2009). Fences and artificial water affect African savannah elephant movement patterns. Biological Conservation, 142(12), 3086-3098. doi:10.1016/j.biocon.2009.08.008 
Lutz, C. K., \& Novak, M. A. (2005). Environmental enrichment for nonhuman primates: Theory and application. Institute for Laboratory Animal Research Journal, 46(2), 178-191. doi:10.1093/ilar.46.2.178

MacDonald, S. E. (1994). Gorillas' (Gorilla gorilla gorilla) spatial memory in a foraging task. Journal of Comparative Psychology, 108(2), 107. doi:10.1037/0735-7036.108.2.107

MacDonald, S. E. (2015). Problem solving and exploratory behavior in wild urban and rural raccoons: Cognitive evolution in action? Manuscript submitted for publication.

MacDonald, S. E., \& Agnes, M. M. (1999). Orangutan (Pongo pygmaeus abelii) spatial memory and behavior in a foraging task. Journal of Comparative Psychology, 113(2), 213. doi:10.1037/0735-7036.113.2.213

MacDonald, S. E., Pang, J. C., \& Gibeault, S. (1994). Marmoset (Callithrix jacchus jacchus) spatial memory in a foraging task: Win-stay versus win-shift strategies. Journal of Comparative Psychology, 108(4), 328. doi:10.1037/0735-7036.108.4.328

MacDonald, S. E., \& Pinel, J. P. (1991). Information gathering: A component of the defensive behavior of rats and Old-World monkeys. The Psychological Record 41, 207-215. Retrieved from http://psycnet.apa.org/psycinfo/1991-26603-001

MacDonald, S. E., Spetch, M. L., Kelly, D. M., \& Cheng, K. (2004). Strategies in landmark use by children, adults and marmoset monkeys. Learning and Motivation, 35, 322-347. doi:10.1016/j.lmot.2004.03.002

MacDonald, S. E., \& Wilkie, D. M. (1990). Yellownosed monkeys' (Cercopithecus ascanius whitesidei) spatial memory in a simulated foraging environment. Journal of Comparative Psychology, 104(4), 382. doi:10.1037/0735-7036.104.4.382

Marsh, H. L., Adams, L., Floyd, C., \& MacDonald, S. E. (2013). Feature versus spatial strategies by orangutans (Pongo abelii) and human children (Homo sapiens) in a cross-dimensional task. Journal of Comparative Psychology, 127(2), 128. doi:10.1037/a0030591
Marsh, H. L., \& MacDonald, S. E. (2008). The use of perceptual features in categorization by orangutans (Pongo abelli). Animal Cognition, 11(4), 569-585. doi:10.1007/s10071-008-0148-1

Marsh, H. L., \& MacDonald, S. E. (2011). Information seeking by orangutans: A generalized search strategy? Animal Cognition, 15(3), 293-304. doi:10.1007/s10071-011-0453-y

Marsh, H. L., \& MacDonald, S. E. (2012). Orangutans (Pongo abelii) "play the odds": Information-seeking strategies in relation to cost, risk, and benefit. Journal of Comparative Psychology, 126(3), 263. doi:10.1037/a0025906

Marsh, H. L., Spetch, M. L., \& MacDonald, S. E. (2011). Strategies in landmark use by orangutans and human children. Animal Cognition, 14(4), 487-502. doi:10.1007/s10071-011-0382-9

Mason, G., Clubb, R., Latham, N., \& Vickery, S. (2007). Why and how should we use environmental enrichment to tackle stereotypic behaviour? Applied Animal Behaviour Science, 102(3-4), 163-188. doi:10.1016/j.applanim.2006.05.041

Menzel, R., Greggers, U., Smith, A., Berger, S., Brandt, R., Brunke, S., . . Watzl, S. (2005). Honey bees navigate according to a map-like spatial memory. Proceedings of the National Academy of Sciences of the United States of America, 102(8), 3040-3045. doi:10.1073/pnas.0408550102

Morris, R. (1984). Developments of a water-maze procedure for studying spatial learning in the rat. Journal of Neuroscience Methods, 11(1), 47-60. doi:10.1016/0165-0270(84)90007-4

Narendra, A., Si, A., Sulikowski, D., \& Cheng, K. (2007). Learning, retention and coding of nest-associated visual cues by the Australian desert ant, Melophorus bagoti. Behavioral Ecology and Sociobiology, 61(10), 1543-1553. doi:10.1007/s00265-007-0386-2

Olton, D. S., \& Samuelson, R. J. (1976). Remembrance of places passed: Spatial memory in rats. Journal of Experimental Psychology: Animal Behavior Processes, 2(2), 97. doi:10.1037/0097-7403.2.2.97 
Osborn, F. V., \& Parker, G. E. (2002). Community-based methods to reduce crop loss to elephants: Experiments in the communal lands of Zimbabwe. Pachyderm, 33, $32-38$.

Osborn, F. V., \& Parker, G. E. (2003). Towards an integrated approach for reducing the conflict between elephants and people: A review of current research. Oryx, 37(1), 80-84. doi:10.1017/S0030605303000152

Perry, S., \& Manson, J. H. (2003). Traditions in monkeys. Evolutionary Anthropology: Issues, News, and Reviews, 12(2), 1-81. doi:10.1002/evan.10105

Plotnik, J. M., Lair, R., Suphachoksahakun, W., \& de Waal, F. B. M. (2011). Elephants know when they need a helping trunk in a cooperative task. Proceedings of the National Academy of Sciences, 108(12), 5116-5121. doi:10.1073/pnas.1101765108

Plotnik, J. M., de Waal, F. B. M., \& Reiss, D. (2006). Selfrecognition in an Asian elephant. Proceedings of the National Academy of Sciences, 103(45), 17053-17057. doi:10.1073/pnas.0608062103

Pravosudov, V. V., \& Clayton, N. S. (2002). A test of the adaptive specialization hypothesis: Population differences in caching, memory, and the hippocampus in black-capped chickadees (Poecile atricapilla). Behavioral Neuroscience, 116(4), 515. doi:10.1037/0735-7044.116.4.515

Renner, M. J., \& Kelly, A. L. (2006). Behavioral decisions for managing social distance and aggression in captive polar bears (Ursus maritimus). Journal of Applied Animal Welfare Science 9(3), 333-339. doi:10.1207/s15327604jaws0903_5

Ritvo, S. E., Allison, R. S., (2014). Challenges related to nonhuman animal-computer interaction: Usability and "liking." In Adjunct Proceedings of the International Conference on Advances in Computer Entertainment Technology - Workshop on Animal Human Computer Interaction (ACE '14). Funchal, Madeira. doi:10.1145/2693787.2693795

Ritvo, S. E., \& MacDonald, S. E. (unpublished manuscript). Music preference and discrimination in three Sumatran orangutans (Pongo abelii). York University (Canada), Toronto, Canada.
Roberts, W. A., \& Grant, D. S. (1976). Studies of shortterm memory in the pigeon using the delayed matching to sample procedure. In D. L. Medin, W. A. Roberts, \& R. T. Davis (Eds.), Processes of animal memory, 79-112. Hillsdale, NJ: Erlbaum.

Roitblat, H.L., Terrace, H.S., \& Bever, T.G. (Eds.). (1984). Animal Cognition. Hillsdale, NJ: Lawrence Erlbaum Associates.

Saudargas, R. A., \& Drummer, L. C. (1996). Single subject $($ small N) research designs and zoo research. Zoo Biology, 15(2), 173-181. http://dx.doi.org/10.1002 /(SICI)1098-2361(1996)15:2<173::AIDZOO7>3.0.CO;2-8

Sherry, D. F., Jacobs, L. F., \& Gaulin, S. J. C. (1992). Spatial memory and adaptive specialization of the hippocampus. Trends in Neurosciences, 15(8), 298-303. doi:10.1016/0166-2236(92)90080-R

Shettleworth, S. J. (1972). Constraints on learning. Journal of Experimental Psychology: Animal Behavior Processes, 8(4), 354-375. doi:10.1016/S0065-3454(08)60006-6

Shettleworth, S. J. (1990). Spatial memory in foodstoring birds. Philosophical Transactions of the Royal Society of London B: Biological Sciences, 329(1253), 143-151. doi:10.1098/rstb.1990.0159

Shettleworth, S. J., \& Krebs, J. R. (1982). How marsh tits find their hoards: The roles of site preference and spatial memory. Journal of Experimental Psychology: Animal Behavior Processes, 8(4), 354. doi:10.1037/0097-7403.8.4.354

Sitati, N. W., \& Walpole, M. J. (2006). Assessing farmbased measures for mitigating human-elephant conflict in Transmara district, Kenya. Oryx, 40(3), 279-286. doi:10.1017/S0030605306000834

Sitati, N. W., Walpole, M. J., \& Leader-Williams, N. (2005). Factors affecting susceptibility of farms to crop raiding by African elephants: Using a predictive model to mitigate conflict. Journal of Applied Ecology, 42(6), 1175-1182. doi:10.1111/j.1365-2664.2005.01091.x 
Smith, C., Philips, A., \& Reichard, M. (2015). Cognitive ability is heritable and predicts the success of an alternative mating tactic. Proceedings of the Royal Society B, 282(1809), 20151046. doi:10.1098/rspb.2015.1046

Spetch, M. L., \& Honig, W. K. (1988). Characteristics of pigeons' spatial working memory in an open-field task. Animal Learning \& Behavior, 16(2), 123-131. doi:10.3758/BF03209054

Stoinski, T. S., Wrate, J. L., Ure, N., \& Whiten, A. (2001). Imitative learning by captive western lowland gorillas (Gorilla gorilla gorilla) in a simulated food-processing task. Journal of Comparative Psychology, 115(3), 272. doi:10.1037/0735-7036.115.3.272

Suzuki, S., Augerinos, G., \& Black, A. H. (1980). Stimulus control of spatial behavior on the eight-arm maze in rats. Learning and Motivation, 11(1), 1-18. doi:10.1016/0023-9690(80)90018-1

Thornton, A., \& Raihani, N. J. (2010). Identifying teaching in wild animals. Learning \& Behavior, 38(3), 297-309. doi:10.3758/LB.38.3.297

Tresz, H. (2006). Behavioral management at the Phoenix Zoo: New strategies and perspectives. Journal of Applied Animal Welfare Science, 9(1): 65-70. doi:10.1207/s15327604jaws0901_6

von Bayern, A. M. P., Heathcote, R. J. P., Rutz, C., $\&$ Kacelnik, A. (2009). The role of experience in problem solving and innovative tool use in crows. Current Biology, 19(22), 1965-1968. doi:10.1016/j.cub.2009.10.037

Vonk, J., \& MacDonald, S. E. (2002). Natural concepts in a juvenile gorilla (Gorilla gorilla gorilla) at three levels of abstraction. Journal of the Experimental Analysis of Behavior, 78(3), 315-332. doi:10.1901/jeab.2002.78-315

Vonk, J., \& MacDonald, S. E. (2004). Levels of abstraction in orangutan (Pongo abelii) categorization. Journal of Comparative Psychology, 118(1), 3. doi:10.1037/0735-7036.118.1.3
Watters, J. V., \& Powell, D. M. (2012). Measuring animal personality for use in population management in zoos: Suggested methods and rationale. Zoo Biology, 31(1), 1-12. doi:10.1002/zoo.20379

Webster, S. J., \& Lefebvre, L. (2001). Problem solving and neophobia in a columbiform-passeriform assemblage in Barbados. Animal Behaviour, 62(1), 23-32. doi:10.1006/anbe.2000.1725

Weed, J. L., \& O’Neill-Wagner, P. L. (2015). Animal behaviour research findings facilitate comprehensive captive animal care: The birth of behavioral management. Retrieved August 31, 2015, from http://awic.nal.usda.gov/environmental-enrichment -nonhuman-primates-resource-guide-animal-behavior -research-findings.

Whiten, A., Horner, V., \& de Waal, F. B. M. (2005). Conformity to cultural norms of tool use in chimpanzees. Nature, 437(7059), 737-740. doi:10.1038/nature04047

Wystrach, A., Beugnon, G., \& Cheng, K. (2012). Landmarks or panoramas: What do navigating ants attend to for guidance? Frontiers in Zoology, 8(1), 21-21. doi:10.1186/1742-9994-8-21

Xitco, M. J., Gory, J. D., \& Kuczaj, S. A. (2001). Spontaneous pointing by bottlenose dolphins (Tursiops truncates). Animal Cognition, 4(2), 115-123. doi: 10.1007/s100710100107

Xitco, M. J., Gory, J. D., \& Kuczaj, S. A. (2004). Dolphin pointing is linked to the attentional behavior of a receiver. Animal Cognition, 7(4), 231-238. doi: 10.1007/s10071-004-0217-z

Zentall, T., \& Hogan, D. (1974). Abstract concept learning in the pigeon. Journal of Experimental Psychology, 102(3), 393. doi: 10.1037/h0035970

Zitzer, H., \& MacDonald, S. E. (2015). The role of food preferences in habitat damage by wild African elephants (Loxodonta africana). Manuscript in preparation. 